\title{
Socioeconomic and demographic factors modify the association between informal caregiving and health in the Sandwich Generation
}

\author{
Elizabeth $\mathrm{K} \mathrm{Do}^{1,3}$, Steven A Cohen ${ }^{2^{*}}$ and Monique J Brown ${ }^{2}$
}

\begin{abstract}
Background: Nearly 50 million Americans provide informal care to an older relative or friend. Many are members of the "sandwich generation", providing care for elderly parents and children simultaneously. Although evidence suggests that the negative health consequences of caregiving are more severe for sandwiched caregivers, little is known about how these associations vary by sociodemographic factors.

Methods: We abstracted data from the Behavioral Risk Factor Surveillance System to determine how the association between caregiving and health varies by sociodemographic factors, using ordinal logistic regression with interaction terms and stratification by number of children, income, and race/ethnicity.

Results: The association between informal caregiving and health varied by membership in the "sandwich generation," income, and race/ethnicity. This association was significant among subjects with one $(\mathrm{OR}=1.13,95 \%$ $\mathrm{Cl}[1.04,1.24])$ and two or more children $(\mathrm{OR}=1.17,95 \% \mathrm{Cl}=1.09,1.26])$, but not in those without children $(\mathrm{OR}=1.01,95 \% \mathrm{Cl}[0.97,1.05])$. Associations were strongest in those earning $\$ 50,000-\$ 75,000$ annually, but these income-dependent associations varied by race/ethnicity. In Whites with two or more children, the strongest associations between caregiving and health occurred in lower income individuals. These trends were not observed for Whites without children.

Conclusions: Our findings suggest that the added burden of caregiving for both children and elderly relatives may be impacted by income and race/ethnicity. These differences should be considered when developing culturally appropriate interventions to improve caregiver health and maintain this vital component of the US health care system.
\end{abstract}

Keywords: Informal caregiving, Older population, Race/ethnicity, Income, Children

\section{Background}

The United States (US) population aged 65 years and older is expected to increase from 34 million in 2006 [1] to 71 million by the year 2030 [2]. Within this population are a growing number of elderly persons with chronic health conditions who require special social services and/or informal caregiving by family members and friends. Approximately a quarter of US households provide informal caregiving to an older relative or friend

\footnotetext{
* Correspondence: scohen@vcu.edu

${ }^{2}$ Department of Family Medicine and Population Health, Division of Epidemiology, Virginia Commonwealth University, 830 East Main Street- 8th Floor, Richmond, Virginia 23298, USA

Full list of author information is available at the end of the article
}

[2]. Overall, informal caregiving has resulted in over $\$ 350$ billion dollars annually in economic savings for the US [3]. However, the maintenance of such responsibility can result in caregiver stress, leading to negative physical and mental health consequences [4-8] including: loss or reduction in employment $[9,10]$ and decreased quality in childcare [11,12] and marital relationships [13].

Caregivers are forced to miss an average of 6.6 days of work annually due to their caregiving responsibilities [14]. More than one-third of caregivers providing care to older adults eventually choose to reduce work hours, or leave the workforce entirely. Relative to men, women are more likely to leave their jobs once they begin providing care. Both of these options have long-term financial

\section{C) Biomed Central}


implications for caregivers, including an immediate loss of income and/or potential savings [1].

The role of caregiving and resultant caregiver stress varies by race/ethnicity $[15,16]$. In dementia caregivers, depression is more common among Whites than in African-Americans, and Whites report caregiving as a more stressful activity than other racial/ethnic groups [17]. Also, the relationship between caregiving and specific health outcomes differs by race/ethnicity. In a study of spousal caregivers, the positive association between informal caregiving and cardiovascular disease was evident in Whites, but not for non-Whites [18].

The impacts of informal caregiving are especially evident in the "sandwich generation" [6], the group of individuals who provide simultaneous care to their young or adolescent children and an older family member or friend [19]. According to a 2001 study, two of every five Americans between the ages of 45 and 55 are caregivers to both their parents and children under the age of 21 [17]. A small, but growing body of evidence suggests that members of the sandwich generation may be at higher risk for impaired health behaviors since caregiving reduces the amount of time available for engaging in personal health behaviors. However, few studies have investigated the association between caregiving and health, comparing caregivers of older adults alone to caregivers of both older adults and children.

Therefore, the objective of this study is to determine how the association between caregiving and caregiver health varies by whether or not the caregiver is also providing care to children, as well as race/ethnicity and socioeconomic status.

\section{Methods}

\section{Study population}

Publicly available data were abstracted from the Behavioral Risk Factor Surveillance System (BRFSS), a federally funded, nationally representative survey of the civilian, non-institutionalized, adult population aged 18 years or older. The CDC and state health departments conduct this survey annually to monitor healthrelated behaviors and risk factors in the US population. In 2009, all 50 states, plus the District of Columbia, and the three US territories participated in the survey. For each selected household, one adult is randomly identified and interviewed for BRFSS. The median cooperation rate was $75.0 \%$ and the median overall response rate was $52.5 \%$ [20]. A detailed description of the BRFSS study methodology and survey sampling techniques are available online [21]. The BRFSS study has been approved by Human Research Review Boards from the state departments of health.

To examine the association between caregiving and health, subjects who had missing information on the primary outcome, exposure, and effect modification variables were excluded from analyses.

\section{Outcome measurement}

The main outcome of interest was asked of all 2009 BRFSS participants. Each respondent was asked "Would you say that in general your health is: excellent, very good, good, fair, or poor?" This measure was analyzed as a Likert scale with 1 representing "excellent" and 5 representing "poor" self-reported general health, and has been used in previous studies [22,23].

\section{Exposure measurements}

The primary exposure of interest in the study was caregiving status, as measured by the question previously utilized and tested in prior versions of the BRFSS survey [24,25], "People may provide regular care or assistance to a friend or family member who has a health problem, long-term illness, or disability. During the past month, did you provide any such care or assistance to a friend or family member?" Potential confounders assessed in this analysis included age, sex, BMI, rurality, employment, race/ethnicity, income, and number of children. Age and BMI were analyzed as continuous variables. Rurality was based upon the tertile of population density. Race/ethnicity was based on five calculated categories provided by the BRFSS: Non-Hispanic White, Non-Hispanic Black, Non-Hispanic Asian, Hispanic, and Other. Income was derived from the BRFSS categories. Income was grouped into four categories: $<\$ 25,000$, $\$ 25,000-<\$ 50,000, \$ 50,000-<\$ 75,000$, and $\geq \$ 75,000$. The number of children under 18 years of age was analyzed as an ordinal variable with three levels: 0,1 , or $2+$ children. Race/ethnicity, income, and number of children were also used as effect modification variables to determine if and how the association between caregiving and health varies among sociodemographic groups, the primary objective of the study.

\section{Statistical analyses}

Socioeconomic, demographic, and health characteristics of the study sample were tabulated using mean values of continuous variables and frequencies of categorical variables. Then, ordinal logistic regressions were used to calculate odds ratios (OR) and associated 95\% confidence intervals (CI) for the outcome of general health status. ORs above 1 indicate increased odds of reporting poorer general health, and ORs below 1 indicate decreased odds of reporting poorer general health. Both unadjusted and adjusted models were used.

Tests for potential effect modification by number of children, income, and race/ethnicity were conducted, through inclusion of two-way interaction terms and through stratification by number of children, income, and race/ethnicity separately and jointly. Finally, linear trends in the potential 
effect modification for each of these three factors were tested. Appropriate BRFSS survey weights that account for unequal selection probabilities, non-response, and oversampling were applied for all analyses using PROC SURVEYFREQ in SAS (version 9.3; SAS Institute, Cary, NC) software. This research received no specific grant from any funding agency in the public, commercial or not-for-profit sectors.

\section{Results}

Socioeconomic and demographic characteristics of the analytic sample are displayed in Table 1. From the 440,314 total participants who completed the telephone interview, complete data were available for 292,813 individuals who were included in the final analysis. Of those, 74,135 were self-identified as caregivers and 216,652 were not caregivers. Compared to the overall gender distribution $(51.4 \%$

Table 1 Demographic characteristics of the behavioral risk factor surveillance system sample comparing caregivers to non-caregivers

\begin{tabular}{|c|c|c|c|c|}
\hline & Overall & Caregivers & Non-caregivers & P-value \\
\hline $\mathrm{N}$ & 292813 & $74135(24.1)$ & $216652(75.3)$ & \\
\hline Age (years) & $46.6(46.6,46.7)$ & $47.4(47.3,47.5)$ & $46.4(46.3,46.5)$ & $<0.001$ \\
\hline \multicolumn{5}{|l|}{ Sex } \\
\hline Females & $181449(51.4)$ & $50163(56.9)$ & 131286 (49.6) & \multirow[t]{2}{*}{$<0.001$} \\
\hline Males & 109338 (48.6) & $23972(43.1)$ & $85366(50.4)$ & \\
\hline BMI (kg/m2) & $27.50(27.48,27.52)$ & $27.76(27.71,27.80)$ & $27.43(27.40,27.46)$ & $<0.001$ \\
\hline \multicolumn{5}{|c|}{ Type of community } \\
\hline Rural & $97257(20.2)$ & $25732(21.6)$ & $71525(19.8)$ & \multirow[t]{3}{*}{$<0.001$} \\
\hline Intermediate & $97113(35.2)$ & $24781(35.7)$ & $72332(35.0)$ & \\
\hline Urban & $96417(44.6)$ & $23622(42.8)$ & $72795(45.2)$ & \\
\hline \multicolumn{5}{|l|}{ Race } \\
\hline White & $231650(68.9)$ & $58798(69.8)$ & 172852 (68.6) & \multirow[t]{5}{*}{$<0.001$} \\
\hline Black & $25630(10.5)$ & $7382(12.3)$ & $18248(9.9)$ & \\
\hline Asian & $3614(3.4)$ & $645(2.4)$ & $2969(3.7)$ & \\
\hline Hispanic & 18065 (13.8) & $3914(11.3)$ & $14151(14.6)$ & \\
\hline Other & $9164(3.5)$ & $2716(4.2)$ & $6448(3.2)$ & \\
\hline \multicolumn{5}{|l|}{ Works for wages } \\
\hline Yes & $144557(57.2)$ & $38803(57.1)$ & $105754(57.3)$ & \multirow[t]{2}{*}{$<0.001$} \\
\hline No & $145577(42.8)$ & $35185(42.9)$ & $110392(42.7)$ & \\
\hline \multicolumn{5}{|l|}{ Income } \\
\hline $0-25 k$ & $72994(22.9)$ & $17609(22.8)$ & $55385(22.9)$ & \multirow[t]{5}{*}{$<0.001$} \\
\hline $25-50 \mathrm{k}$ & $68154(21.8)$ & $18596(23.3)$ & $49558(21.3)$ & \\
\hline $50-75 k$ & $41242(14.2)$ & $11127(14.4)$ & $30115(14.2)$ & \\
\hline $75 \mathrm{k}+$ & $71809(29.4)$ & $18532(28.7)$ & $53277(29.6)$ & \\
\hline Missing & $36578(11.7)$ & $8266(10.8)$ & $28312(12.0)$ & \\
\hline \multicolumn{5}{|l|}{ Children } \\
\hline None & $207042(56.8)$ & $52990(59.5)$ & $154052(56.0)$ & \multirow[t]{3}{*}{$<0.001$} \\
\hline 1 & $33395(17.0)$ & 9097 (16.8) & $24298(17.0)$ & \\
\hline $2+$ & $49951(26.2)$ & $11959(23.7)$ & $37792(27.0)$ & \\
\hline \multicolumn{5}{|c|}{ Self-reported health } \\
\hline Excellent & $52642(20.9)$ & $13067(19.5)$ & $39575(21.4)$ & \multirow[t]{5}{*}{$<0.001$} \\
\hline Very good & 92757 (33.4) & $24117(32.5)$ & $68640(33.6)$ & \\
\hline Good & $87736(29.8)$ & $23022(31.3)$ & $64714(29.3)$ & \\
\hline Fair & 39087 (11.8) & $10073(12.7)$ & $29014(11.5)$ & \\
\hline Poor & $16671(4.2)$ & 3452 (3.9) & $13219(4.3)$ & \\
\hline
\end{tabular}


female, $48.6 \%$ male), a disproportionate amount of females (56.9\%) were caregivers compared to males (43.1\%). Caregivers had slightly higher BMIs than non-caregivers, and were, on average, one year older than non-caregivers. Noncaregivers were slightly more likely to have had at least one child compared to caregivers. Caregivers were less likely to report excellent or very good health compared to noncaregivers.

Poorer health was associated with caregiving, increasing age, male sex, increasing BMI, non-White race/ethnicity, low income, and having no children (Table 2). Examining two-way interactions of race, income, and number of children with caregiving status and their association with selfreported health status, we found that the associations between caregiving and self-reported health varied considerably by number of children. There were statistically significant and fairly consistent interactions showing that compared to individuals without young children, the impact of caregiving on health was more detrimental in individuals with one child under 18 (OR 1.11, 95\% CI [1.01, 1.23]). The magnitude of the interaction was even more pronounced in individuals with at least two children (OR

Table 2 Parameter estimates for ordinal logistic regression models: unadjusted (Model 1), adjusted for socioeconomic and demographic characteristics (Models 2 and 3), and adjusted for socioeconomic and demographic characteristics with interactions for race/ethnicity (Model 4), income (Model 5), number of children (Model 6), and all three (Model 7)

\begin{tabular}{|c|c|c|c|c|c|c|c|}
\hline & Model 1 & Model 2 & Model 3 & Model 4 & Model 5 & Model 6 & Model 7 \\
\hline Caregiving & $1.11(1.07,1.14)$ & $1.07(1.03,1.11)$ & $1.07(1.04,1.11)$ & $1.08(1.05,1.12)$ & $1.07(1.01,1.12)$ & $1.01(0.97,1.06)$ & $1.01(0.96,1.08)$ \\
\hline Age (years) & & $1.01(1.01,1.01)$ & $1.02(1.02,1.02)$ & $1.02(1.02,1.02)$ & $1.02(1.02,1.02)$ & $1.02(1.02,1.02)$ & $1.02(1.02,1.02)$ \\
\hline Sex & & $0.99(0.96,1.02)$ & $0.96(0.94,0.99)$ & $0.96(0.94,0.99)$ & $0.96(0.94,0.99)$ & $0.96(0.94,0.99)$ & $0.96(0.49,0.99)$ \\
\hline BMI (kg/m2) & & $1.09(1.08,1.09)$ & $1.08(1.08,1.08)$ & $1.08(1.08,1.08)$ & $1.08(1.08,1.08)$ & $1.08(1.08,1.08)$ & $1.08(1.08,1.08)$ \\
\hline \multicolumn{8}{|l|}{ Type of community } \\
\hline Rural & & $1.19(1.15,1.23)$ & $1.18(1.14,1.22)$ & $1.18(1.14,1.22)$ & $1.18(1.14,1.22)$ & $1.18(1.14,1.22)$ & $1.18(1.14,1.22)$ \\
\hline Intermediate & & $1.02(0.99,1.05)$ & $1.08(1.05,1.12)$ & $1.08(1.05,1.11)$ & $1.08(1.05,1.12)$ & $1.08(1.05,1.12)$ & $1.08(1.05,1.12)$ \\
\hline Works for wages & & $0.47(0.45,0.48)$ & $0.60(0.58,0.62)$ & $0.60(0.58,0.62)$ & $0.60(0.58,0.62)$ & $0.60(0.58,0.62)$ & $0.60(0.58,0.62)$ \\
\hline \multicolumn{8}{|l|}{ Race (ref = white) } \\
\hline Black & & & $1.35(1.28,1.42)$ & $1.37(1.29,1.45)$ & $1.35(1.28,1.42)$ & $1.35(1.28,1.42)$ & $1.37(1.29,1.46)$ \\
\hline Asian & & & $1.37(1.23,1.52)$ & $1.35(1.20,1.51)$ & $1.37(1.23,1.52)$ & $1.37(1.23,1.52)$ & $1.35(1.20,1.52)$ \\
\hline Hispanic & & & $1.69(1.60,1.80)$ & $1.74(1.63,1.85)$ & $1.69(1.60,1.80)$ & $1.70(1.60,1.80)$ & $1.76(1.65,1.87)$ \\
\hline Other & & & $1.36(1.25,1.48)$ & $1.33(1.20,1.47)$ & $1.36(1.25,1.48)$ & $1.37(1.23,1.52)$ & $1.33(1.21,1.48)$ \\
\hline \multicolumn{8}{|l|}{ Income (ref = $75 \mathrm{k}+)$} \\
\hline $0-25 k$ & & & $3.14(3.01,3.28)$ & $3.14(3.00,3.28)$ & $3.15(3.00,3.30)$ & $3.14(3.00,3.28)$ & $3.12(2.97,3.27)$ \\
\hline $25-50 \mathrm{k}$ & & & $1.62(1.56,1.69)$ & $1.62(1.56,1.69)$ & $1.62(1.55,1.69)$ & $1.62(1.56,1.68)$ & $1.61(1.55,1.68)$ \\
\hline $50-75 k$ & & & $1.17(1.13,1.22)$ & $1.17(1.13,1.22)$ & $1.16(1.11,1.22)$ & $1.17(1.13,1.22)$ & $1.16(1.11,1.21)$ \\
\hline \multicolumn{8}{|l|}{ Children (ref = none) } \\
\hline 1 child & & & $0.97(0.92,1.01)$ & $0.97(0.92,1.01)$ & $0.97(0.92,1.01)$ & $0.94(0.90,0.99)$ & $0.94(0.89,0.99)$ \\
\hline 2 or more children & & & $0.86(0.82,0.90)$ & $0.86(0.82,0.89)$ & $0.86(0.82,0.89)$ & $0.83(0.79,0.87)$ & $0.82(0.79,0.86)$ \\
\hline \multicolumn{8}{|l|}{ Race-caregiving intx } \\
\hline Black $\times$ Caregiving & & & & $0.96(0.85,1.08)$ & & & $0.94(0.84,1.06)$ \\
\hline Asian $\times$ Caregiving & & & & $1.11(0.84,1.48)$ & & & $1.10(0.83,1.46)$ \\
\hline Hispanic x Caregiving & & & & $0.88(0.75,1.04)$ & & & $0.86(0.73,1.01)$ \\
\hline Other $\times$ Caregiving & & & & $1.08(0.89,1.31)$ & & & $1.06(0.87,1.29)$ \\
\hline \multicolumn{8}{|l|}{ Income-caregiving intx } \\
\hline 0-25 k x Caregiving & & & & & $0.99(0.90,1.08)$ & & $1.02(0.93,1.12)$ \\
\hline 25-50 k x Caregiving & & & & & $1.00(0.90,1.09)$ & & $1.02(0.93,1.12)$ \\
\hline 50-75 k x Caregiving & & & & & $1.03(0.94,1.12)$ & & $1.03(0.94,1.13)$ \\
\hline \multicolumn{8}{|l|}{ Children-caregiving intx } \\
\hline 1 child $\times$ Caregiving & & & & & & $1.10(1.00,1.21)$ & $1.11(1.01,1.23)$ \\
\hline $2+$ children $\times$ Caregiving & & & & & & $1.17(1.08,1.26)$ & $1.18(1.09,1.28)$ \\
\hline
\end{tabular}


$1.18,95 \%$ CI $[1.09,1.28])$ in the full model. However, none of the race-caregiving and income-caregiving interactions were statistically significant in these models.

\section{Race/Ethnicity}

The association between caregiving and health varied by race/ethnicity. Overall, there was a small, but statistically significant association between caregiving and poor health $(\mathrm{OR}=1.07,95 \% \mathrm{CI}[1.03,1.11])$ (Table 3). Similar results were observed for Whites $(\mathrm{OR}=1.10,95 \% \mathrm{CI}$ $[1.07,1.14])$ and Others $(\mathrm{OR}=1.21,95 \% \mathrm{CI}[1.01,1.45])$. No significant associations were observed for Blacks, Asians, or Hispanics, when considering each racial/ethnic group separately.

Table 3 Parameter estimates for adjusted ordinal logistic regression models stratified by race/ethnicity, income, and number of children

\begin{tabular}{|c|c|c|c|c|c|c|}
\hline & & Overall & 0 & 1 & $2+$ & $p$ for child trend \\
\hline \multirow[t]{6}{*}{ All races } & All incomes & $1.07(1.03,1.11)$ & $1.01(0.97,1.05)$ & $1.13(1.04,1.24)$ & $1.17(1.09,1.26)$ & 0.540 \\
\hline & $<25$ & $1.03(0.96,1.11)$ & $0.96(0.88,1.04)$ & $0.98(0.81,1.17)$ & $1.23(1.05,1.47)$ & 0.009 \\
\hline & $25-50$ & $1.08(1.00,1.16)$ & $1.03(0.94,1.12)$ & $1.25(1.03,1.51)$ & $1.10(0.94,1.29)$ & 0.058 \\
\hline & $50-75$ & $1.13(1.04,1.22)$ & $1.03(0.94,1.13)$ & $1.15(0.95,1.39)$ & $1.38(1.14,1.66)$ & 0.067 \\
\hline & $75+$ & $1.16(1.09,1.23)$ & $1.15(1.05,1.24)$ & $1.24(1.07,1.44)$ & $1.12(1.01,1.25)$ & $<0.001(\mathrm{a})$ \\
\hline & $P$-value for inc trend & $<0.001$ & $<0.001$ & $<0.001$ & $<0.001(\mathrm{a})$ & \\
\hline \multirow[t]{6}{*}{ White } & All incomes & $1.10(1.07,1.14)$ & $1.02(0.98,1.06)$ & $1.25(1.14,1.37)$ & $1.27(1.18,1.37)$ & 0.100 \\
\hline & $<25$ & $1.16(1.08,1.25)$ & $1.05(0.97,1.15)$ & $1.15(0.93,1.42)$ & $1.58(1.28,1.95)$ & 0.016 \\
\hline & $25-50$ & $1.16(1.09,1.23)$ & $1.08(1.01,1.16)$ & $1.37(1.12,1.69)$ & $1.31(1.11,1.56)$ & 0.197 \\
\hline & $50-75$ & $1.09(1.01,1.18)$ & $1.04(0.94,1.14)$ & $1.07(0.86,1.32)$ & $1.28(1.07,1.54)$ & 0.691 \\
\hline & $75+$ & $1.12(1.05,1.19)$ & $1.09(1.01,1.18)$ & $1.29(1.11,1.50)$ & $1.07(0.96,1.19)$ & $0.011(\mathrm{a})$ \\
\hline & P-value for inc trend & $0.004(\mathrm{a})$ & 0.191 & 0.074 & $<0.001(\mathrm{a})$ & \\
\hline \multirow[t]{6}{*}{ Black } & All incomes & $1.09(0.98,1.22)$ & $0.97(0.84,1.12)$ & $1.09(0.84,1.40)$ & $1.38(1.09,1.74)$ & 0.302 \\
\hline & $<25$ & $0.93(0.78,1.11)$ & $0.88(0.70,1.10)$ & $1.04(0.67,1.62)$ & $1.07(0.77,1.47)$ & 0.642 \\
\hline & $25-50$ & $1.08(0.86,1.35)$ & $1.03(0.78,1.37)$ & $0.96(0.59,1.57)$ & $1.30(0.78,2.17)$ & 0.789 \\
\hline & $50-75$ & $1.27(0.93,1.75)$ & $0.76(0.52,1.01)$ & $1.59(0.93,2.73)$ & $2.79(1.38,5.62)$ & 0.003 \\
\hline & $75+$ & $1.30(0.97,1.74)$ & $1.25(0.81,1.93)$ & $0.88(0.49,1.59)$ & $1.50(0.90,2.48)$ & 0.645 \\
\hline & $P$-value for inc trend & $<0.001$ & $<0.001$ & 0.395 & 0.020 & \\
\hline \multirow[t]{6}{*}{ Asian } & All incomes & $1.17(0.89,1.54)$ & $1.07(0.72,1.59)$ & $1.24(0.66,2.31)$ & $1.32(0.84,2.07)$ & 0.969 \\
\hline & $<25$ & $1.20(0.66,2.16)$ & $1.24(0.59,2.63)$ & $1.10(0.49,2.51)$ & $1.35(0.71,2.56)$ & 0.724 \\
\hline & $25-50$ & $1.28(0.64,2.55)$ & $0.87(0.34,2.28)$ & $2.38(0.87,6.52)$ & $3.23(1.11,9.44)$ & 0.040 \\
\hline & $50-75$ & $1.33(0.54,3.27)$ & $0.97(0.35,2.74)$ & $0.75(0.08,7.31)$ & $3.23(0.55,19.14)$ & 0.207 \\
\hline & $75+$ & $1.31(0.90,1.92)$ & $1.43(0.82,2.50)$ & $1.26(0.62,2.56)$ & $1.29(0.71,2.34)$ & 0.403 \\
\hline & P-value for inc trend & 0.933 & 0.100 & 0.240 & 0.070 & \\
\hline \multirow[t]{6}{*}{ Hispanic } & All incomes & $0.91(0.78,1.06)$ & $0.92(0.72,1.18)$ & $0.82(0.61,1.10)$ & $1.00(0.81,1.24)$ & 0.201 \\
\hline & $<25$ & $0.90(0.73,1.11)$ & $0.85(0.63,1.15)$ & $0.80(0.52,1.23)$ & $1.18(0.85,1.63)$ & 0.175 \\
\hline & $25-50$ & $0.82(0.59,1.15)$ & $0.79(0.44,1.42)$ & $1.00(0.53,1.88)$ & $0.81(0.54,1.23)$ & 0.302 \\
\hline & $50-75$ & $1.20(0.84,1.73)$ & $1.92(1.15,3.23)$ & $0.94(0.45,1.96)$ & $0.76(0.40,1.43)$ & 0.160 \\
\hline & $75+$ & $1.57(1.11,2.21)$ & $1.71(1.08,2.72)$ & $1.12(0.50,2.50)$ & $1.38(0.85,2.26)$ & 0.182 \\
\hline & P-value for inc trend & $<0.001$ & $<0.001$ & 0.579 & 0.758 & \\
\hline \multirow[t]{6}{*}{ Other } & All incomes & $1.21(1.01,1.45)$ & $0.97(0.77,1.22)$ & $1.40(0.94,2.08)$ & $1.66(1.13,2.44)$ & 0.684 \\
\hline & $<25$ & $1.16(0.84,1.60)$ & $0.97(0.70,1.36)$ & $0.84(0.36,1.94)$ & $1.71(0.85,3.46)$ & 0.954 \\
\hline & $25-50$ & $1.12(0.79,1.60)$ & $0.89(0.59,1.34)$ & $2.21(0.96,5.06)$ & $1.06(0.48,2.35)$ & 0.659 \\
\hline & $50-75$ & $1.62(1.04,2.52)$ & $0.89(0.51,1.54)$ & $1.73(0.75,4.03)$ & $4.85(1.95,12.04)$ & 0.006 \\
\hline & $75+$ & $1.06(0.76,1.50)$ & $0.79(0.47,1.31)$ & $1.54(0.70,3.39)$ & $1.39(0.74,2.60)$ & 0.971 \\
\hline & P-value for inc trend & 0.489 & 0.268 & 0.372 & 0.357 & \\
\hline
\end{tabular}

(a) Indicates that the linear trend was negative. 


\section{Number of children}

In the models simultaneously stratified by income, race/ ethnicity, and number of children, the association between self-reported health and informal caregiving varied substantially by these three sociodemographic factors. Examining the subgroup of subjects with no children under age 18 in the household, the association between caregiving and health was not significant (OR $=1.01,95 \% \mathrm{CI}[0.97,1.05]$ ). However, the association between caregiving and health was statistically significant in subjects with one $(\mathrm{OR}=1.13$, $95 \%$ CI $[1.04,1.24])$ or two or more children $(\mathrm{OR}=1.17$, $95 \% \mathrm{CI}=1.09,1.26])$. However, the trend with increased number of children was not significant. In individuals earning less than $\$ 25,000$ per year, there was a significant positive trend in the association between caregiving and health by increasing numbers of children $(\mathrm{p}<0.009)$. For those earning above $\$ 75,000$ per year, the association between caregiving and health was statistically significant for the entire subgroup, regardless of the number of children. Similar results were observed in Whites. For Blacks, the association between caregiving and health increased as the number of children in the family increased, but the trend was significant only in those earning between $\$ 50,000$ and $\$ 75,000$ annually $(\mathrm{p}=0.003)$.

\section{Income}

Considering all races and family sizes combined, as income increased, the magnitude of the association between caregiving and health increased, as well $(\mathrm{p}<0.001)$. When stratified by race/ethnicity, this positive trend indicating an increasing association of caregiving and health as income increased was present in Hispanics $(\mathrm{p}<0.001)$ and also in Blacks, though marginally significant $(\mathrm{p}=0.064)$. For Whites, there was actually a significant negative linear trend in income as a modifier of the association between caregiving and health $(\mathrm{p}<0.001)$; indicating that as income increased, the association between caregiving and health decreased. The observed trend was small, but statistically significant.

For the entire sample, when stratified by number of children, income was a positive effect modifier of the association between caregiving and health in people without children or with one child ( $p<0.001$ for both groups). The opposite occurred in people with two or more children; for those subjects, as income increased, the association between caregiving and poor health actually decreased $(\mathrm{p}<0.001)$.

\section{Discussion}

The association between caregiving and the self-reported health status of caregivers varied by sociodemographic factors, including number of children present within a household, race/ethnicity, and income. We found that the association between caregiving and poor health generally increased with the number of children present within a household. This finding suggests that there may be increased caregiver stress among the sandwich generation of adults that care for both their elderly family members or friends and underage children simultaneously. Such observations are consistent with past studies [19] suggesting that members of the sandwich generation may be at higher risk for impaired health behaviors compared to caregivers who provide care only for an older adult.

Regarding differences by race/ethnicity in the association between caregiving and health status, there was a statistically significant association between caregiving and health among Whites and Others. This association was not observed for Blacks, Asians, or Hispanics, indicating that cultural differences may exist influencing the association between caregiving and health status. Cultural differences may influence perceptions of caregiving, as they relate to the availability and use of coping strategies by caregivers to manage their situations [26]. For example, other studies examining this association have identified cultural expectations [27], identity [28], family functioning [29], social support [27,30], and spirituality [27] as potential factors influencing perceptions of caregiving. These factors may help to explain some of the observed individual differences in stress response to the caregiving burden [30] and may be interesting topics to explore in future research.

The association between caregiving and health also varied by income. Curiously, the association tended to be strongest in the intermediate income group earning between $\$ 50,000$ and $\$ 75,000$ per year and in those earning $\$ 75,000$ or more, although these findings were not observed for Hispanics. The directionality of the interaction with income changed as the number of children increased for the overall sample. The nonlinear function between health and income has also been observed previously. In one study, stroke rates and income had a non-linear association, with high rates for low and high income groups, and low rates for middle income groups in one study [31].

The overall trends by income were more difficult to detect within the race/ethnicity subgroups. In Whites, the association between caregiving and health was inconsistently significant as income increased. However, for Whites with at least two children, the association between caregiving and poorer health increased significantly $(\mathrm{p}<0.001)$ as income decreased. This finding suggests that, in Whites, caregiving for both elderly relatives and children may be more burdensome in individuals with fewer economic resources than in individuals with higher socioeconomic status. Although the specific reason for the observed trends remains unclear, one potential explanation is that the variability in health among lower income individuals was slightly higher than in those with higher incomes. Those in the lowest 
quartile of income had approximately $20 \%$ higher variability in the health status outcome variable compared to those in the highest income quartile. Therefore, there is the potential to observe a stronger relationship in the lower income groups due to the increased variability of the outcome, which may account for some of the observed trends by income.

An interesting paradox was found, as well. In the models that contained interaction terms (Table 2), the interactions between race and caregiving, and income and caregiving were not statistically significant. However, in the stratified models, there were substantial differences in the association between caregiving and health by both race and income categories. The reasons for this are unclear and require further investigation. Such findings could be due, in part, to the overall magnitude of the effect modification occurring, as well as the observation that the direction and strength of the effect modification by income did not occur uniformly within all race categories, and therefore would not be detected as significant in the interaction models.

\section{Study limitations and future research directions}

Although our study contributes to the growing literature on caregiving burden experienced by the sandwich generation, results should be interpreted with caution, given its limitations. First, the use of cross-sectional data limited the study's ability to make causal claims regarding the association of caregiving and health status. Second, we only used one measure of self-reported health status as our outcome of interest. Future studies should examine multiple outcomes to allow for a more comprehensive assessment of caregiver health. Third, income thresholds were limited by those provided by the survey questionnaire. Missing data could also bias the observed results somewhat. The relatively small amount of missing data for health status $(0.7 \%)$, number of children in the households $(0.1 \%)$, and race/ethnicity $(0.9 \%)$ should not affect the results meaningfully. However, $12.7 \%$ of eligible respondents did not report income. Among those not reporting income, their average self-reported health status was between those in the lowest and second-lowest income categories. Therefore, people who were less healthy were slightly less likely to report income than healthier respondents, which may bias the observed results. Finally, despite having a large sample size, the observed associations between caregiving and health were clinically quite modest in magnitude, although many were statistically significant.

Directions for future research could include other health outcomes, such as emotional, mental, and physical health measures. Additionally, future studies should examine the potential for the observed associations varying by gender. Previous studies have found that female caregivers experience significantly greater strain in family relationships and declines in health than males [32]. Among caregivers to older adults with dementia, females had significantly more caregiver burden than males [33]. Male caregivers to individuals with dementia have a higher desire to institutionalize their relatives with dementia than females when the quality of the relationship between caregiver and recipient is low, but such differences were negligible when quality of the relationship was high [34]. Thus, there is a distinct need to understand the roles, responsibilities, and effects of caregiving, which might also be explained by gender.

Future studies could also examine, among caregivers, how the overall intensity of caregiving, defined by length of time spent caregiving, hours per week caregiving, and specific activities of daily living and instrumental activities of daily living with which the caregiver assists the care recipient, are associated with caregiver burden with respect to health and well-being. These associations could also be assessed by whether or not the caregiver is a "sandwiched" caregiver. Promising new data sets, such as the National Study of Caregiving, a subset of the new National Health and Aging Trends Study (NHATS) [35], could assist in providing detailed data on both the caregiver and the care recipient to better understand these associations.

\section{Conclusion}

Our study suggests that the association between informal caregiving and health varies by whether or not the caregiver is a member of the "sandwich generation", income, and race/ethnicity. In general, the association between caregiving and health was strongest in those with more children, but there were important racial/ethnic and incomeassociated differences in these trends. These important sociodemographic differences should be considered when developing culturally-appropriate policies and programs designed to improve the health of caregivers, in efforts to maintain this invaluable part of the health care system in the US.

\section{Competing interests}

The authors declare that they have no competing interests.

\section{Authors' contributions}

EKD developed the objective of the manuscript and wrote the background and discussion sections. SAC refined the objective of the manuscript, performed the statistical analysis, and wrote the methods and results sections. MJB contributed to the background and discussion sections and edited the entire manuscript. All authors read and approved the final manuscript.

\section{Author details}

${ }^{1}$ Virginia Institute of Psychiatric and Behavioral Genetics, Virginia Commonwealth University, Richmond, Virginia, USA. ${ }^{2}$ Department of Family Medicine and Population Health, Division of Epidemiology, Virginia Commonwealth University, 830 East Main Street- 8th Floor, Richmond, 
Virginia 23298, USA. ${ }^{3}$ Center for Clinical and Translational Research, Virginia Commonwealth University, Richmond, Virginia, USA.

Received: 16 July 2013 Accepted: 26 March 2014 Published: 15 April 2014

\section{References}

1. MetLife Mature Market Institute: The MetLife Study of Caregiving Costs to Working Caregivers: Double Jeopardy for Baby Boomers Caring for their Parents; 2011. Available: http://www.aarp.org/relationships/caregiving/info07-2011/caregivers-save-us-health-care-system-money.html. Accessed December 28, 2012.

2. Durant TJ, Christian OG: Caregiving to Aging Parents Forum on Public Policy. Available: http://forumonpublicpolicy.com/archive07/durant.pdf. Accessed December 9.

3. Gibson MJ, Houser A: Valuing the invaluable: a new look at the economic value of family caregiving. Issue Brief (Public Policy Inst (Am Assoc Retired Pers)) 2007, IB82:1-12.

4. Covinsky KE, Newcomer R, Fox P, Wood J, Sands L, Dane K, Yaffe K: Patient and caregiver characteristics associated with depression in caregivers of patients with dementia. J Gen Intern Med 2003, 18:1006-1014.

5. Kiecolt-Glaser JK, Preacher K, MacCallum RC, Atkinson C, Malarkey WB, Glaser R: Chronic stress and age-related increases in the proinflammatory cytokine IL-6. Proc Natl Acad Sci U S A 2003, 100:9090-9095.

6. Riley LD, Bowen C: The Sandwich Generation: challenges and coping strategies of multigenerational families. Fam J 2005, 13:52-58.

7. Cannuscio CC, Jones C, Kawachi I, Colditz GA, Berkman L, Rimm E: Reverberations of family illness: a longitudinal assessment of informal caregiving and mental health status in the nurses' health study. Am J Public Health 2002, 92(8):1305-1311.

8. Schulz R, O'Brien AT, Bookwala J, Fleissner K: Psychiatric and physical morbidity effects of dementia caregiving: prevalence, correlates, and causes. Gerontologist 1995, 35(6):771-791.

9. Berecki-Gisolf J, Lucke J, Hockey R, Dobson A: Transitions into informal caregiving and out of paid employment of women in their 50s. Soc Sci Med 2008, 67:122-127.

10. Scharlach AE: Caregiving and employment: competing or complementary roles? Gerontologist 1994, 34:378-385.

11. Chassin L, Macy JT, Seo DC, Presson CC, Sherman SJ: The association between membership in the Sandwich Generation and health behaviors: a longitudinal study. J Appl Dev Psychol 2010, 31:38-46.

12. Rogerson PA, Kim D: Population distribution and redistribution of the baby-boom cohort in the United States: recent trends and implications. Proc Natl Acad Sci U S A 2005, 102:15319-15324.

13. Brody EM, Litvin SJ, Hoffman C, Kleban MH: Differential effects of daughters' marital status on their parent care experiences. Gerontologist 1992, 32:58-67.

14. Witters D: The cost of caregiving to the U.S. economy. GALLUP Business J Available: http://businessjournal.gallup.com/content/151049/cost-caregivingeconomy.aspx. Accessed December 28, 2012.

15. Cravey T, Mitra A: Demographics of the sandwich generation by race and ethnicity in the United States. J Socio-Economics 2011, 40:306-311.

16. Aranda MP, Knight BG: The influence of ethnicity and culture on the caregiver stress and coping process: a sociocultural review and analysis. Gerontologist 1997, 37:342-354.

17. Janevic MR, Connell CM: Racial, ethnic, and cultural differences in the dementia caregiving experience: recent findings. Gerontologist 2001, 41:334-347.

18. Capistrant BD, Moon JR, Berkman LF, Glymour MM: Current and long-term spousal caregiving and onset of cardiovascular disease. J Epidemiol Community Health 2012, 66:951-956.

19. Chisholm JF: The sandwich generation. J Social Distress Homeless 1999, 8:177-180.

20. Centers for Disease Control and Prevention (CDC): 2009 BRFSS Summary data quality report; 2010. Available: http://www.cdc.gov/brfss/annual_data/ 2009/2009_Summary_Data_Quality_Report.docx. Accessed December 12, 2012.

21. Centers for Disease Control and Prevention (CDC): 2009 BRFSS overview 2010. Available: http://www.cdc.gov/brfss/annual_data/2009/overview_09.rtf. Accessed December 12, 2012
22. Mokdad AH, Ford ES, Bowman BA, Dietz WH, Vinicor F, Bales VS, Marks JS: Prevalence of obesity, diabetes, and obesity-related health risk factors, 2001. JAMA 2003, 289:76-79.

23. Arnadottir SA, Gunnarsdottir ED, Stenlund H, Lundin-Olsson L: Determinants of self-rated health in old age: a population-based, cross-sectional study using the International Classification of Functioning. BMC Public Health 2011, 11:670.

24. Wilcox S, Castro C, King AC, Housemann R, Brownson RC: Determinants of leisure time physical activity in rural compared with urban older and ethnically diverse women in the United States. J Epidemiol Community Health 2000, 54:667-672.

25. Centers for Disease Control and Prevention (CDC): Characteristics and health of caregivers and care recipients-North Carolina, 2005. MMWR Morb Mortal Wkly Rep 2007, 56:529-532.

26. Herrera A, Mendez-Luck CA, Crist JD, Smith ML, Warre R, Ory MG, Markides $K:$ Psychosocial and cognitive health differences by caregiver status among older Mexican Americans. Community Ment Health J 2013, 49:61-72.

27. Lee Y, Smith L: Qualitative research on Korean American dementia caregivers' perception of caregiving: heterogeneity between spouse caregivers and child caregivers. J Human Behav Soc Environ 2012, 22:115-129.

28. Turner Goins R, Spencer S, McGuire LC, Goldberg J, Wen Y, Henderson JA: Adult caregiving among American Indians: the role of cultural factors. Gerontologist 2011, 51:310-320.

29. Chiou CJ, Chang H, Chen IP, Wang HH: Social support and caregiving circumstances as predictors of caregiver burden in Taiwan. Arch Gerontol Geriatr 2009, 48:419-424.

30. Rodakowski J, Skidmore ER, Rogers JC, Schulz R: Role of social support in predicting caregiver burden. Arch Phys Med Rehabil 2012, 93:2229-2236.

31. Han D, Carrow SS, Rogerson PA, Munschauer FE: Geographical variation of cerebrovascular disease in New York State: the correlation with income. Int J Health Geogr 2005, 4:25-34.

32. Barber CE, Pasley BK: Family care of Alzheimer's patients: the role of gender and generational relationship on caregiver outcomes. $J$ Appl Geront 1995, 14:172-192.

33. Gallicchio L, Siddiqi N, Langenberg P, Baumgarten M: Gender differences in burden and depression among informal caregivers of demented elders in the community. Int J Geriatr Psychiatry 2002, 17:154-163.

34. Winter $L$, Gitlin $L N$, Dennis M: Desire to institutionalize a relative with dementia: quality of premorbid relationship and caregiver gender. Fam Relations 2011, 60:221-230.

35. The National Health and Aging Trends Study. URL: http://www.nhats.org/ Accessed 2/28/14

doi:10.1186/1471-2458-14-362

Cite this article as: Do et al:: Socioeconomic and demographic factors modify the association between informal caregiving and health in the Sandwich Generation. BMC Public Health 2014 14:362.

\section{Submit your next manuscript to BioMed Central and take full advantage of:}

- Convenient online submission

- Thorough peer review

- No space constraints or color figure charges

- Immediate publication on acceptance

- Inclusion in PubMed, CAS, Scopus and Google Scholar

- Research which is freely available for redistribution

Submit your manuscript at www.biomedcentral.com/submit
C Biomed Central 